\title{
Trypanosoma cruzi: Genetic Group with Peculiar Biochemical and Biological Behavior
}

\author{
Mônica Lúcia Gomes/ ${ }^{+}$, Max Jean de Ornelas Toledo, Celso Vataru Nakamura, \\ Nilza de Lucas Rodrigues Bittencourt, Egler Chiari*, Silvana Marques de Araújo
}

\author{
Departamento de Análises Clínicas, Universidade Estadual de Maringá, Av. Colombo 5790, 87020-900 Maringá, PR, Brasil \\ *Departamento de Parasitologia, ICB/UFMG, Belo Horizonte, MG, Brasil
}

Thirty-two Trypanosoma cruzi strains, isolated from chronic chagasic patients in the northwest of the state of Paraná (Brazil), were analyzed using molecular, biochemical and biological characteristics. Genotypic analysis using randomly amplified polymorphic DNA and simple sequence repeat-anchored polymerase chain reaction amplified profiles showed a large, genetically well-correlated group that contained the majority of the strains and a divergent group that included the PR-150 strain. For glycoconjugate composition, the PR-150 strain was different from the other strains considering the absence or presence of specific bands in aqueous or detergent phases. This strain was also totally different from the others in one out of the six parameters related to in vitro and in vivo biological behavior. We highlight the fact that the PR-150 was totally resistant to benznidazole. For the other biological parameters this strain was not totally distinct from the others, but it showed a peculiar behavior.

Key words: Trypanosoma cruzi - randomly amplified polymorphic DNA (RAPD) - simple sequence repeat-anchored polymerase chain reaction amplified (SSR-PCR) - glycoconjugates - biological characteristics

The course of Trypanosoma cruzi infection varies widely in endemic areas (Dias 1992). The reasons for this variability are unknown, but there is evidence that parasite and host factors and their interaction influence the evolution of Chagas disease. Many studies have been conducted aiming to find correlations among biological, biochemical and molecular characteristics of parasite populations and clinical variations of Chagas disease.

T. cruzi populations present a considerable biological and genetic variability (Morel et al. 1980, Dvorak 1984, Tibayrenc \& Ayala 1988, Carneiro et al. 1991, Macedo et al. 1992, Steindel et al. 1993, Oliveira et al. 1997). Biochemical characteristics have also been used to classify trypanosomatids. Besides isoenzyme analysis (Miles et al. 1977, Tibayrenc et al. 1986), specific patterns of glycoconjugates have been used as markers in phylogenic and taxonomic studies of trypanosomatids (Branquinha et al. 1995).

Tibayrenc et al. (1986) have proposed that T. cruzi undergoes predominant clonal evolution with only rare events of genetic recombination. This clonal model predicts a parallel evolution between biological differences and genetic divergence among $T$. cruzi natural clones. Some results have shown a strong statistical linkage between genetic and biological differences using $T$. cruzi cloned stocks representing three or four major clonal geno-

Financial support: Conselho Nacional de Desenvolvimento Científico e Tecnológico, Fundação Nacional de Saúde, Universidade Estadual de Maringá

${ }^{+}$Corresponding author. Fax: +55-44-261.4490. E-mail: mlgomes@uem.br

Received 4 December 2002

Accepted 3 June 2003 types of the parasite (Laurent et al. 1997, Revollo et al. 1998, Diego et al. 1998, Toledo et al. 2002, 2003).

In this study, we showed two distinct genetic groups for T. cruzi strains, highlighting that one group differ from the other in biochemical and biological parameters studied.

\section{MATERIALS AND METHODS}

T. cruzi strains - In this study 32 T. cruzi strains isolated from chronic chagasic patients by hemoculture were used (Chiari et al. 1989). These patients originally came from different geographical localities, but were currently living in the northwest of the state of Paraná, Brazil. Seventeen strains were isolated from patients from the state of Minas Gerais (MG), 8 from the state of São Paulo (SP), 4 from the state of Paraná (PR), and 3 from Northeastern Brazil: Bahia (BA), Paraíba (PB) and Alagoas (AL) (Table I). These strains were grown in Liver Infusion Tryptose (LIT) medium and cryopreserved at $-196^{\circ} \mathrm{C}$ in liquid nitrogen.

Molecular characterization - Thirty out of the $32 \mathrm{~T}$. cruzi strains were grown in LIT and RAPD (randomly amplified polymorphic DNA) and SSR-PCR (simple sequence repeat-anchored polymerase chain reaction amplified) profiles were determined. The parasites were washed three times in Krebs Ringer Tris buffer (KRT). Total DNA was extracted as described by Macedo et al. (1992). RAPD profiles using three different arbitrary primers (L15996 5'CTCCACCATTAGCACCCAAAGC3'; M1340 5'GTTTTCCCAGTCACGAC3'; $\lambda$ gt11 5'GACTCC TGGAGCCCG3') and SSR-PCR with the $(\mathrm{CA})_{8} \mathrm{RY}$ primer $(\mathrm{R}=$ purine, and $\mathrm{P}=$ pyrimidine $)$ were determined according to Oliveira et al. (1997). The multiband profiles of $T$. cruzi strains resulting from RAPD and SSR-PCR were submitted to unweighted pair group method analysis (UPGMA) in order to build a phenetic tree in the MEGA program (Kumar et al. 1993). 
TABLE I

Strains of Trypanosoma cruzi isolated from chronic chagasic patients living in northwest Paraná, Southern Brazil

\begin{tabular}{lcl}
\hline Strains & (Code) & Origin \\
\hline PR-2259 & (A) & Virgem da Lapa/MG \\
PR-150 & (B) & Januária/MG \\
PR-379 & (C) & Londrina/PR \\
PR-328 & (D) & Congoninhas/PR \\
PR-316 & (E) & Minas Novas/MG \\
PR-396 & (F) & Lassance/MG \\
PR-501/89 & (G) & Santa Cruz do Rio Pardo/SP \\
PR-501/94 & (H) & Santa Cruz do Rio Pardo/SP \\
PR-182 & (I) & Itamarandiba/MG \\
PR-184 & (J) & Montes Claros/MG \\
PR-149 & (K) & Montes Claros/MG \\
PR-001 & (L) & Araçuaí/MG \\
PR-2784 & (M) & Iepê/SP \\
PR-387 & (N) & Sebastião Laranjeira/BA \\
PR-101 & (O) & Capelinha da Graça/MG \\
PR-655 & (P) & Brasília de Minas/MG \\
PR-1256 & (Q) & União dos Palmares/AL \\
PR-057 & (R) & Santa Deli/SP \\
PR-034 & (S) & Grão Mogol/MG \\
PR-068 & (T) & Cerqueira Cesar/SP \\
PR-036 & (U) & São Pedro Turvo/SP \\
PR-367 & (V) & Teófilo Otoni/MG \\
PR-1921 & (W) & Paraguaçu/SP \\
PR-1055 & (X) & Conceição do Piancó/PB \\
PR-2052 & (Y) & Mirasselva/PR \\
PR-458 & (Z) & Florinea/SP \\
PR-399 & (b) & \\
PR-401 de Maio/PR & (c) & Berile/MG \\
PR-402 & (d) & Poté/MG \\
PR-427 & (e) & Terra Branca/MG \\
PR-076 & (f) & Coração de Jesus/MG \\
PR-209 & (g) & Montes Claros/MG \\
\hline & &
\end{tabular}

Biochemical characterization - Eleven T. cruzi strains were grown in LIT medium and were tested for glycoconjugate composition. Cells were solubilized overnight at $0^{\circ} \mathrm{C}$ in $10 \mathrm{mM}$ Tris saline buffer, $\mathrm{pH} 7.4$, containing $2 \%$ Triton X-114. Insoluble material was removed from the lysate by centrifugation at $20000 \mathrm{~g}$ for $20 \mathrm{~min}$. The aqueous and detergent phases were separated with $6 \%$ sucrose cushion $(1: 1.5, \mathrm{vol} / \mathrm{vol})$ and analyzed in SDS-PAGE gel. Gels were stained using periodic acid-Schiff reagent (Laemmli 1970, Bordier 1981).

Biological characterization - T. cruzi strains were analyzed using in vitro and in vivo biological parameters including (1) growth and (2) metacyclogenesis rates, (3) infectivity of culture forms to mice, (4) parasitaemia patterns, (5) mortality and (6) susceptibility to benznidazole in mice.

Growth and metacyclogenesis rates were evaluated for 20 strains of T. cruzi using M16 (Chiari et al. 1980) and LIT media. For each sample, parasites from exponential growth phase in LIT medium were seeded in $15 \mathrm{ml}$ of each medium to obtain a final concentration of $1.5 \times 10^{7}$ flagellates $/ \mathrm{ml}$. Growth and epimastigote-trypomastigote differentiation rates were evaluated at days 2, 4, 6 and 8 of culture.
The infectivity of culture-derived trypomastigotes to $\mathrm{C} 3 \mathrm{H} / \mathrm{He}$ mice was determined by observation of patent parasitaemia by fresh blood examination or subpatent parasitaemia by hemoculture. Mice were inoculated with $0.3 \mathrm{ml}$ of eighth-day culture with a percentage of trypomastigotes ranging from 1 to $74 \%$, according to each strain.

Parasitaemia patterns were evaluated for 26 out of the 32 T. cruzi strains studied. Groups of five $\mathrm{C}_{3} \mathrm{H} / \mathrm{HE}$ mice were inoculated, by i.p. route, with $5 \times 10^{3}$ blood trypomastigotes (BT) of each strain. Parasitaemia was determined by fresh blood examination and the number of parasites was registered daily according to Brener (1962), starting on the 4 th day of infection. Curves were plotted using the mean of parasitaemia observed in mice from each group. Strains that determined subpatent parasitaemia in mice or up to $10^{3}$ parasites $/ \mathrm{ml}$ were considered of low parasitaemia. Strains with patent parasitaemia from $10^{4}$ to $10^{5}$ parasites $/ \mathrm{ml}$ were considered of medium parasitaemia, and those with parasitaemia of the order of $10^{6}$ parasites $/ \mathrm{ml}$ or more were considered of high parasitaemia. Mortality was registered for a period of up to 120 days post-inoculation and expressed as a cumulative mortality percentage.

Susceptibility to benznidazole was evaluated in 13 out of the 32 strains studied. Groups of 20 Swiss mice were inoculated with $1 \times 10^{4}$ BT for 7 strains that reached a parasitaemia peak from $10^{4}$ to $10^{6} \mathrm{BT}$. For 5 strains that reached a parasitaemia peak of $1 \times 10^{3} \mathrm{BT}$, the inoculum was $1 \times 10^{3} \mathrm{BT}$. For strains with subpatent parasitaemia, mice were inoculated with $1.9 \times 10^{7}$ culture-derived trypomastigotes obtained in M16 medium. Ten animals were treated by oral route with benznidazole (RochaganRoche), at a dose of $100 \mathrm{mg} / \mathrm{kg}$ of body weight for 20 consecutive days, beginning as soon as the infection was confirmed by fresh blood examination or hemoculture. This period varied from 10 to 25 days after inoculation. To determine the cure rate for each strain, hemoculture test was used 30 days after the end of the treatment and indirect immunofluorescence reaction - IIF in mice sera was done 6 months after treatment as described by Filardi and Brener (1987). Mice were considered cured when hemoculture and IIF tests were negative. Mice showing IIF titer $\geq 20$ were considered to be therapeutical failures. Ten animals were used as an untreated control for each strain. During the susceptibility experiments the parasitaemia was monitored after the treatment by fresh blood examination for 30 days, 3 times a week, and mortality was not observed in the evaluation period ( 6 months).

\section{RESULTS}

Molecular characterization - The genetic analysis showed the existence of a broad, genetically well-correlated group containing the majority of strains and a divergent group that included only the PR-150 strain. A representative result obtained with L15996 primer with 26 out of the 30 studied strains is presented in Fig. 1. As shown, the majority of the strains display a low genetic variability level detected by an average of $71 \%$ shared bands varying from 200 to 2000 base pairs (bp) in length from the RAPD profiles of the $30 \mathrm{~T}$. cruzi strains using three differ- 


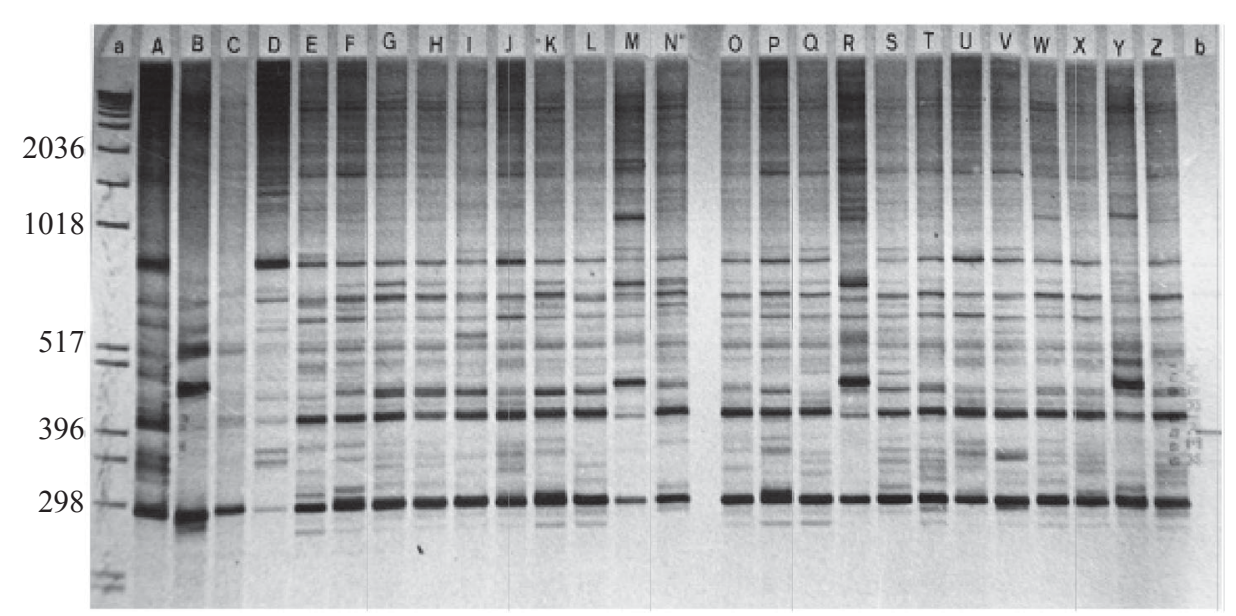

Fig. 1: a silver-stained 5\% polyacrylamide gel containing the L15996 randomly amplified polymorphic DNA profile of 26 Trypanosoma cruzi strains (Lane A-Z) isolated from chronic chagasic patients of different geographical origin. Molecular size markers of the $1 \mathrm{~Kb}$ Ladder (Life, Gaithersburg, MD, US) are shown on the left (a). Lane b represents the negative polymerase chain reaction control.

ent primers. The PR-150 strain displays a RAPD profile completely different from the other strains studied. When the RAPD profiles were used to build a phenetic tree by UPGMA, we obtained a phenogram consisting of a single genetically well-correlated cluster containing $97.6 \%$ of the strains analyzed from different endemic regions (Fig. 2). The SSR-PCR data (not shown) also detected a main cluster involving $93.3 \%$ of the $T$. cruzi strains analyzed and showed great similarity in the general topology of the tree obtained from RAPD data.

Biochemical characterization - The glycoconjugates were detected in the aqueous and detergent phases for the eleven strains studied. Ten strains belonging to one genetic group expressed glycoconjugates with molecular weights of $36 \mathrm{kDa}, 44 \mathrm{kDa}$ and $53 \mathrm{kDa}$ in the aqueous phase and $29 \mathrm{kDa}, 32 \mathrm{kDa}, 44 \mathrm{kDa}$ and $66 \mathrm{kDa}$ in the detergent phase (Table II). In the genetic group containing the PR-150 strain glycoconjugates of $44 \mathrm{kDa}$ and $29 \mathrm{kDa}$ was absent in the aqueous and detergent phases, respectively. On the other hand, bands of $36 \mathrm{kDa}, 39 \mathrm{kDa}$ and $44 \mathrm{kDa}$ were present in the detergent phase for this strain (Table II, Fig. 3).

Biological characterization - Genetic group including the majority of the strains displayed high heterogeneity in the metacyclogenesis rates in M16 medium with an accentuated tendency to produce low levels of epimastigote-trypomastigote transformation. Of the 19 strains evaluated, 13 had a differentiation of 2-27\% in M16 medium. In LIT medium these strains displayed metacyclogenesis rates between 0.8 and $12.2 \%$. Four had a differentiation of 30-51\% in M16 and 3.8-19.4\% in LIT. For PR-2259 and PR-149 strains the differentiation rates were $60.2 \%$ and $74 \%$ in M16, and $57 \%$ and $3.8 \%$ in LIT, respectively (Table II). Parasite growth in LIT medium was in general higher than in M16 medium for the majority of analyzed strains (Table II). Growth in both media was exponential from the beginning of the experiment until day 6 , reaching a plateau on day 8 .

We observed that for all strains, culture-derived trypomastigotes were infective to mice, and the majority of them showed low or medium parasitaemia. In Table II it can be seen that the parasitaemia peak ranges from $6 \times 10^{3}$ to $1.4 \times 10^{6}$ and occurs from day 13 to 32 after infection. Fig. 4 presents the parasitaemia curve of 4 representative T. cruzi strains studied showing polar patterns.

Mortality rates were null for 22 out of the 25 studied strains. Exceptions occurred in the case of PR-501/89,

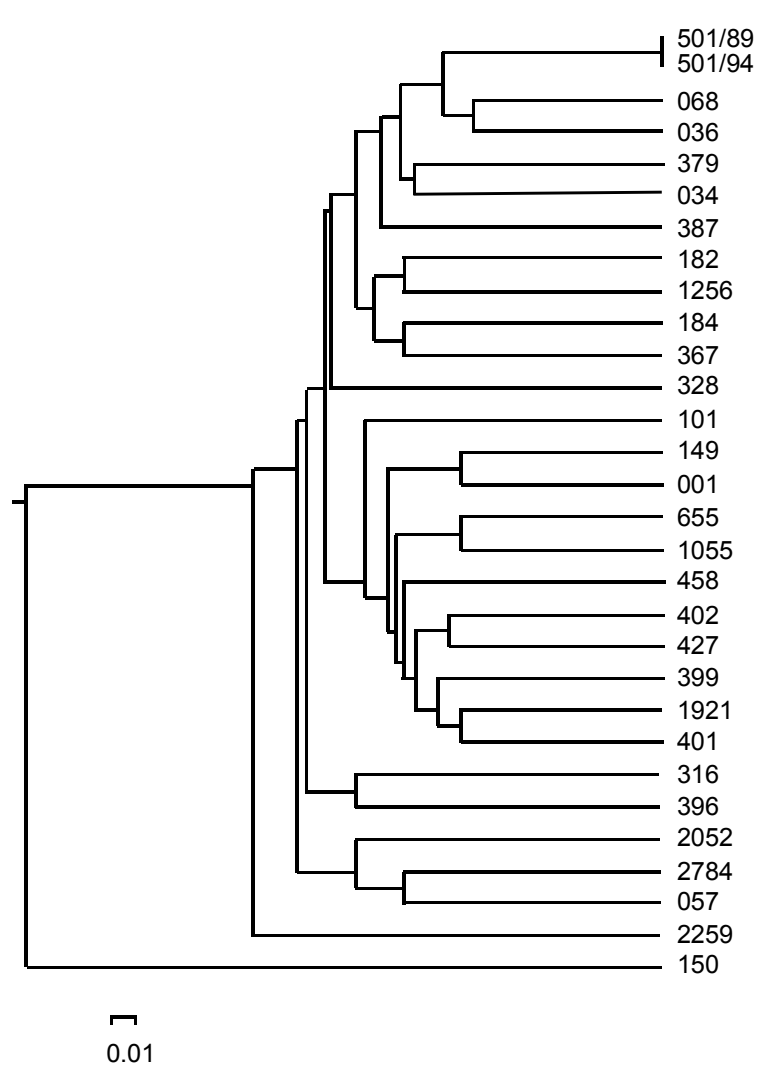

Fig. 2: phenogram of 30 Trypanosoma cruzi strains, constructed by UPGMA method using the genetic distance matrix obtained from randomly amplified polymorphic DNA data by an average of three different arbitrary primers. The scale refers to the D (dissimilarity coefficient) values among the taxa. 


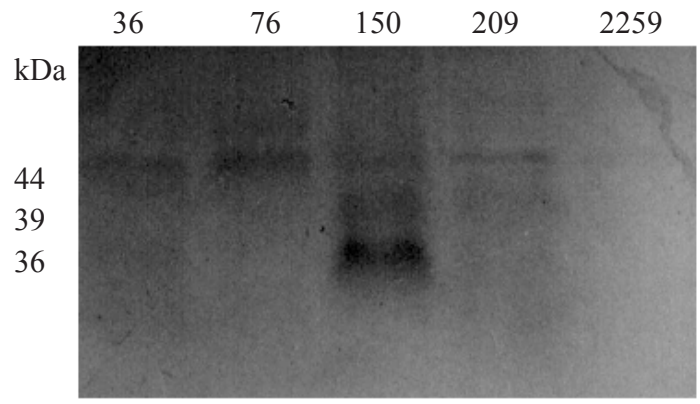

Fig. 3: a periodic acid-Schiff stained sodium dodecyl sulfate polyacrylamide gel electrophoresis containing the glycoprotein pattern obtained in the detergent phase of Trypanosoma cruzi strains.

which had a cumulative mortality rate of $20 \%$ after 15 days of infection, and also in the cases of PR-182 and PR-1055 strains, which had rates of $12.5 \%$ and $25 \%$, respectively (Table II), observed after 100 days of infection.

Susceptibility to benznidazole varied from 15 to $100 \%$ for the 12 strains analyzed, as observed in Table II. Six strains displayed susceptibility between 60 and $100 \%$, six had susceptibility between 15 and $50 \%$.
The biological characteristics from the other genetic group represented by the PR-150 strain can be seen in Table II. We highlighted that this strain presented peculiar biological characteristics such as a high metacyclogenesis rate $(68.6 \%)$ in M16 and a higher proliferation in M16 medium $\left(52.7 \times 10^{6}\right.$ parasites $\left./ \mathrm{ml}\right)$ than in LIT medium $\left(39.4 \times 10^{6}\right.$ parasites $\left./ \mathrm{ml}\right)$. Infectivity of culture-derived trypomastigotes was detected by hemoculture only after the 40th day of culture, showing a scarce number of parasites. We also observed, by optical microscopy, round agglutinated culture forms with short, barely-observable flagella. After successive culture-LIT-passages, epimastigote forms (more wide than long, with short flagellum) prevailed. This characteristic was not observed for strains pertaining to the other genetic group. In addition, mice infected with this strain were unresponsive to benznidazole treatment ( $0 \%$ of cure).

\section{DISCUSSION}

In this paper, molecular analysis displayed two groups, a large, genetically well-correlated group that contained the majority of the strains and a divergent group that included the PR-150 strain. Based on these data, the biological and biochemical characterization was carried out,

TABLE II

Biological characteristics and glycoconjugate composition of Trypanosoma cruzi strains isolated in northwest Paraná, Southern Brazil

\begin{tabular}{|c|c|c|c|c|c|c|c|c|c|}
\hline \multirow[b]{2}{*}{ Strains } & \multicolumn{2}{|c|}{$\begin{array}{c}\text { Nr of parasites } \\
\text { 8th day of } \\
\text { culture }^{a}\end{array}$} & \multicolumn{2}{|c|}{$\begin{array}{l}\text { Metacyclogenesis } \\
\text { (\%) 8th day of } \\
\text { culture }\end{array}$} & \multicolumn{2}{|c|}{$\begin{array}{l}\text { Parasitaemia } \\
\text { peak }\end{array}$} & \multirow{2}{*}{$\begin{array}{l}\text { Cumulative } \\
\text { mortality } \\
(\%)\end{array}$} & \multirow{2}{*}{$\begin{array}{c}\text { Benznidazole } \\
\text { susceptibility } \\
(\%)\end{array}$} & \multirow{2}{*}{$\begin{array}{l}\text { Glycoconjugates } \\
\mathrm{kDa} \\
\text { Aqueous/ } \\
\text { Detergent phases }\end{array}$} \\
\hline & LIT & M16 & LIT & M16 & $\mathrm{BT} \times 10^{3} / \mathrm{ml}$ & Day & & & \\
\hline PR-2259 & 60.5 & 33.4 & 57.0 & 60.2 & 1379 & 30 & 0 & 86 & $36,44,53 / 29,32,44,66$ \\
\hline PR-150 & 39.4 & 52.7 & 22.1 & 68.6 & $\mathrm{SP}$ & ND & 0 & 0 & $36,53 / 36,39,44$ \\
\hline PR-379 & 60.5 & 41.2 & 0.8 & 3.6 & 56 & 16 & 0 & ND & ND \\
\hline PR-328 & ND & ND & ND & ND & PP & ND & 0 & ND & ND \\
\hline PR-316 & 36.8 & 17.3 & 1.4 & 2.2 & 119 & 19 & 0 & ND & ND \\
\hline PR-396 & 51.0 & 36.2 & 1.3 & 5.6 & 56 & 23 & 0 & ND & ND \\
\hline PR-501/89 & 75.0 & 58.0 & 1.5 & 13.4 & 1085 & 16 & 20 & ND & ND \\
\hline PR-182 & 43.3 & 31.0 & 15.0 & 51.0 & 439 & 21 & 12,5 & 15 & $36,44,53 / 29,32,44,66$ \\
\hline PR-184 & 81.5 & 54.5 & 1.0 & 4.6 & 6 & 20 & 0 & 31 & ND \\
\hline PR-149 & 113.8 & 67.5 & 3.8 & 74.0 & 283 & 26 & 0 & 100 & $36,44,53 / 29,32,44,66$ \\
\hline PR-387 & 66.7 & 72.5 & 4.8 & 8.4 & PP & ND & 0 & ND & ND \\
\hline PR-101 & ND & ND & ND & ND & SP & ND & 0 & ND & ND \\
\hline PR-655 & ND & ND & ND & ND & 50 & 25 & 0 & ND & ND \\
\hline PR-1256 & 59.5 & 25.0 & 12.2 & 27.0 & 221 & 17 & 0 & 39 & $36,44,53 / 29,32,44,66$ \\
\hline PR-036 & 44.8 & 29.3 & 1.6 & 2.0 & 140 & 32 & 0 & 75 & $36,44,53 / 29,32,44,66$ \\
\hline PR-367 & 55.0 & 58.0 & 3.8 & 49.0 & PP & ND & 0 & ND & ND \\
\hline PR-1921 & 71.3 & 51.8 & 1.0 & 2.8 & 148 & 19 & 0 & 80 & $36,44,53 / 29,32,44,66$ \\
\hline PR-1055 & ND & ND & ND & ND & 27 & 23 & 25 & ND & ND \\
\hline PR-2052 & ND & ND & ND & ND & SP & ND & 0 & ND & ND \\
\hline PR-458 & ND & ND & ND & ND & 269 & 25 & 0 & ND & ND \\
\hline PR-399 & 109.0 & 96.0 & 5.2 & 22.0 & 49 & 28 & 0 & 100 & ND \\
\hline PR-401 & 102.0 & 80.0 & 1.2 & 10.6 & 49 & 16 & 0 & ND & $36,44,53 / 29,32,44,66$ \\
\hline PR-402 & 52.3 & 60.5 & 11.4 & 30.8 & 98 & 14 & 0 & 35 & $36,44,53 / 29,32,44,66$ \\
\hline PR-427 & 101.8 & 60.0 & 1.6 & 4.2 & 221 & 13 & 0 & 61 & ND \\
\hline PR-076 & 42.3 & 40.8 & 5.6 & 10.4 & 4.8 & 20 & 0 & 40 & $36,44,53 / 29,32,44,66$ \\
\hline PR-209 & 73.0 & 46.5 & 19.4 & 48.8 & 70 & 23 & 0 & 50 & $36,44,53 / 29,32,44,66$ \\
\hline
\end{tabular}

a: $\mathrm{x} 10^{6}$ parasites/ml; PP: patent parasitaemia, but not possible to determine parasitaemia pattern; SP: subpatent parasitaemia; BT: blood trypomastigotes; ND: not done 


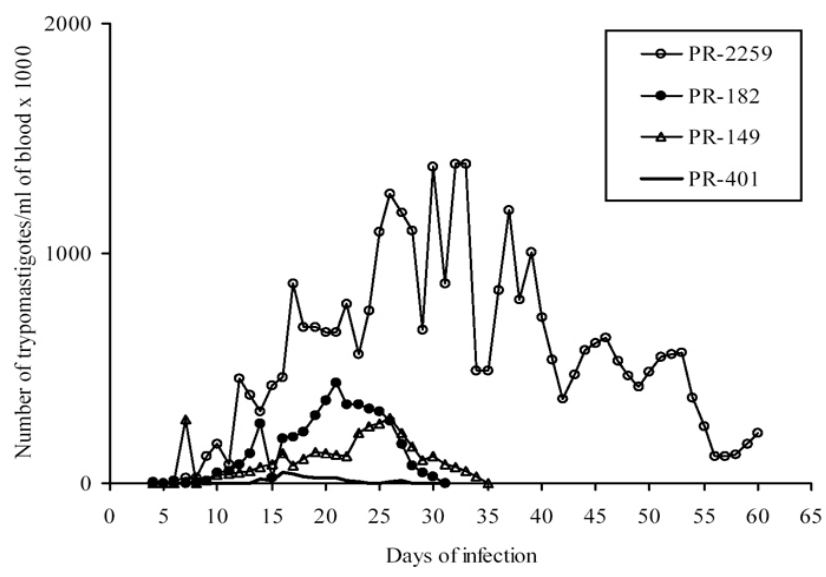

Fig. 4: parasitaemia curves in mice infected with 5000 blood trypomastigotes from four representative Trypanosoma cruzi strains isolated from chronic chagasic patients residing in the state of Paraná.

although it was not performed with all the strains reported here. For the genetic group represented by the PR-150 strain, a different behavior was observed for susceptibility to benznidazole and glycoconjugate profile. For the other biological parameters this strain was not totally distinct from the others, but it showed a peculiar behavior.

Specifically, this strain displayed a total resistance to benznidazole. It showed different glycoconjugate composition, considering the absence or presence of specific bands in aqueous or detergent phases. This strain also displayed other peculiar biological characteristics such as a high metacyclogenesis rate, higher growth in M16 medium than in LIT, and infectivity detected by hemoculture that was positive in a period longer (after the 40th day of culture) than normally observed for other strains, reflecting a low capacity of multiplication in LIT medium.

In general, the peculiar biochemical and biological behavior shown in this paper for a defined genetic group is in agreement with results obtained from different studies that have reported a distinct biological behavior to $T$. cruzi cloned stocks that are genetically distant (Laurent et al. 1997, Revollo et al. 1998, Toledo et al. 2002, 2003).

In this work, biological and genetic parameters presented variability in the group that contained the majority of strains. This variability could be due to the fact that we worked with strains, which were genetically more heterogeneous (Steindel et al. 1993, Tibayrenc et al. 1993) and not with cloned populations of T. cruzi. Studies accomplished by Revollo et al. (1998) and Toledo et al. (2002) with clones of the parasite, exploring accurately the biological parameters, have shown a great standard deviation for biological characteristics in a very defined genetic cluster. These authors have verified that, in spite of this intra-group variability, a significant correlation, but not absolute, exists between the biological and genetic parameters.

Concerning biochemical behavior, the PR-150 strain, representative of one genetic group, displayed a different glycoconjugate composition from the other strains belonging to another group. Giovanni-de-Simone et al. (1988) suggest that Triton X-114 preparations contain an amphiphilic polypeptide which is specific to the CL and Colombian T. cruzi strains when compared to the Dm $28 \mathrm{c}$ clone. Glycoproteins on parasite membranes are most likely targets for an effective immune response. Variations in antigen composition on the surface of $T$. cruzi may have an important role in immunity. Antigens on the parasite surface may serve as targets for trypanolytic antibodies. The different biochemical behavior of the PR-150 strain can be related to the fact that the serum of patient from whom this strain was isolated displayed $0 \%$ lytic activity (complement-mediated lysis, CoML negative) before treatment. It may also be related to the fact that this strain is totally resistant to the drug. Strain-specific antigens may also be relevant for the identification of $T$. cruzi isolates, a fact that may be of great clinical and epidemiological importance including diagnosis. Recent papers have reported that glycoconjugate compositions such as lipophosphoglycan (LPG) and the surface protease gp63 are associated with metacyclogenesis and virulence to Leishmania (Spath et al. 2000, Muskus \& Marin Villa 2002) and also with virulence to Entamoeba sp. (Moody et al. 1997).

It is worth noting that one of our groups that presented peculiar behavior is represented only by the PR150 strain. One possible explanation is that the parasites from this strain do not belong to the T. cruzi species. However, the PR-150 strain was isolated from an asymptomatic patient from Januária, MG. This strain was also infective to Vero cells. In comparative molecular analyses using samples of T. rangeli, Leishmania and other T. cruzi strains, the PR-150 strain grouped with the T. cruzi species. Besides that, unpublished data obtained in our laboratory have shown that the PR-150 strain cluster with a reference strain for T. cruzi II group (Momen 1999). It also clusters with other strains isolated from chagasic patients that are related to the domestic cycle of transmission of this parasite.

The above information gives us evidence that the PR150 strain could belong to T. cruzi II group despite the fact it is totally resistant to benznidazole. This idea is acceptable, considering that although the T. cruzi II strains demonstrate a tendency towards susceptibility to this drug (Andrade \& Magalhães 1997, Toledo et al. 2003) the diversity of behavior inside the T. cruzi II group has been reported (Barnabé et al. 2001). Once more time the peculiar behavior of this strain is evidenced.

Another explanation is that the results could be related to the fact that we only analyzed human strains, or might also be related to the quality of the tools used in this study. Gomes et al. (1998) have shown that one particular strain could be clustered in different groups depending on the technique employed (RAPD or SSR-PCR).

Genetic differences support the theory of typical $T$. cruzi clonal structure (Tibayrenc et al.1986). It was proposed that clonal structure has a major impact on the parasite's biological behavior, including relevant medical properties such as virulence, pathogenicity and resistance to anti-chagasic drugs (Revollo et al. 1998, Toledo et al. 
2003). Many studies have been conducted to search correlation among clinical variations of disease and the diversity of parasite populations. What does the meaning of a T. cruzi genetic group with peculiar biochemical and biological behavior in the natural evolution of Chagas disease? Additional studies with more strains and new approaches could clarify this situation.

\section{REFERENCES}

Andrade SG, Magalhães JB 1997. Biodemes and zymodemes of Trypanosoma cruzi strains: correlations with data and experimental pathology. Rev Soc Bras Med Trop 30: 27-35.

Barnabé B, Neubauer K, Solari A, Tibayrenc M 2001. Trypanosoma cruzi: presence of the two major phylogenetic lineages and of several lesser discrete typing units (DTUs) in Chile and Paraguay. Acta Trop 78: 127-137.

Branquinha MH, Meirelles MNL, Lopes A, Moreira C, Vermelho AB 1995. Use of glycoconjugates for trypanosomatid taxonomy. Current Microbiol 30: 77-82.

Brener Z 1962. Therapeutic activity and criterion of cure in mice experimentally infected with Trypanosoma cruzi. Rev Inst Med Trop São Paulo 4: 389-396.

Bordier C 1981. Phase separation of integral membrane protein in Triton X-114 solution. J Biol Chem 156: 1604-1607.

Carneiro M, Romanha AJ, Chiari E 1991. Biological characterization of Trypanosoma cruzi strains from different zymodemes and schizodemes. Mem Inst Oswaldo Cruz 88: 387-393.

Chiari E, Dias JCP, Lana M, Chiari CA 1989. Hemocultures for the parasitological diagnosis of human chronic Chagas' disease. Rev Soc Bras Med Trop 22: 19-23.

Chiari E, Marques de Araújo S, Carneiro M 1980. Meios empobrecidos em nutrientes na diferenciação epimastigotatripomastigota do Trypanosoma cruzi. VII Reunião Anual em Pesquisa Básica em Doença de Chagas, abst. BI-41.

Dias JCP 1992. Epidemiology of Chagas' disease. In S Wendel, Z Brener, ME Camargo, A Rassi (eds), Chagas' Disease (American Trypanosomiasis): Its Impact on Transfusion and Clinical Medicine, Sociedade Brasileira de Hematologia e Hemoterapia, São Paulo, p. 49-80.

Diego JA, Palau MT, Gamallo C, Penin P 1998. Relationships between histopathological findings and phylogenetic divergence in Trypanosoma cruzi. Trop Med Int Health 3: 222233.

Dvorak JA 1984. The natural heterogeneity of Trypanosoma cruzi: biological and medical implications. J Cel Biochem 24: 357-371.

Filardi L, Brener Z 1987. Susceptibility and natural resistance of Trypanosoma cruzi strains to drugs used clinically in Chagas' disease. Trans R Soc Trop Med Hyg 81: 755-759.

Giovanni-de-Simone S, Bonaldo MC, Pinho RT, Pontes-deCarvalho LC, Galvão-Castro B, Goldenberg S 1988. A study on the amphiphilic proteins of three Trypanosoma cruzi populations. Brazilian J Med Biol Res 21: 435-443.

Gomes ML, Macedo AM, Pena SDJ, Chiari E 1998. Genetic relationships between Trypanosoma cruzi strains isolated from chronic chagasic patients in Southern Brazil as revealed by RAPD and SSR-PCR analysis. Acta Trop 69: 99109.

Kumar S, Koichiro T, Nei M 1993. Mega: Molecular Evolutionary Genetics Analysis, version 1.0, The Pennsylvania State University Park, PA 16802.

Laurent JP, Barnabé C, Quesney V, Noel S, Tibayrenc M 1997. Impact of clonal evolution on the biological diversity of Trypanosoma cruzi. Parasitology 114: 213-218.
Laemmli UK 1970. Cleavage of structural proteins during the assembly of the head of bacteriophage T4. Nature 227: 680-685.

Macedo AM, Martins MS, Chiari E, Pena SDJ 1992. DNA fingerprinting of Trypanosoma cruzi: a new tool for characterization of strains and clones. Mol Biochem Parasitol 55: 147-154.

Miles MA, Toye PJ, Oswald SC, Godfrey DG 1977. The identification by isoenzyme patterns of two distinct straingroups of Trypanosoma cruzi, circulating independently in rural area of Brazil. Trans R Soc Trop Med Hyg 71: 217225.

Momen H 1999. Taxonomy of Trypanosoma cruzi: a commentary on characterization and nomenclature. Mem Inst Oswaldo Cruz 94 (Suppl. 1): 181-184.

Moody S, Becker S, Nuchamowitz Y, Mirelman D 1997. Virulent and avirulent Entamoeba histolytica and E. dispar differ in their cell surface phosphorylated glycolipids. Parasitology 114: 95-104.

Morel CM, Chiari E, Camargo EP, Mattei DM, Romanha AJ, Simpson L 1980. Strains and clones of Trypanosoma cruzi can be characterized by pattern of restriction endonuclease products of kinetoplast DNA minicircles. Proc Natl Acad Sci USA 77: 6810-6814.

Muskus CE, Marin Villa M 2002. Metacyclogenesis: a basic process in the biology of Leishmania. Biomedica 22: 16777.

Oliveira RP, Macedo AM, Chiari E, Pena SDJ 1997. An alternative approach to evaluating the intraspecific genetic variability of parasites. Parasitol Today 13: 196-200.

Revollo S, Oury B, Laurent JP, Barnabé C, Quesney V, Carrière V, Noel S, Tibayrenc M 1998. Trypanosoma cruzi: impact of clonal evolution of the parasite on its biological and medical properties. Exp Parasitol 89: 30-39.

Spath GF, Epstein L, Leader B, Singer SM, Avila HA, Turco SJ, Beverley SM 2000. Lipophosphoglycan is a virulence factor distinct from related glycoconjugates in the protozoan parasite Leishmania major. Proc Natl Acad Sci USA 97: 9258-63.

Steindel M, Neto ED, Menezes CLP, Romanha AJ, Simpson AJG 1993. Random amplified polymorphic DNA analysis of Trypanosoma cruzi strains. Mol Biochem Parasitol 60: 71-80.

Tibayrenc M, Ayala FJ 1988. Isozyme variability in Trypanosoma cruzi, the agent of Chagas' disease: genetical, taxonomical, and epidemiological significance. Evolution 42: 277-292.

Tibayrenc M, Neubauer K, Barnabé C, Guerrini F, Skarecky D, Ayala FJ 1993. Genetic characterization of six parasitic protozoa: parity between random-primer DNA typing and multilocus enzyme electrophoresis. Proc Natl Acad Sci USA 90: 1335-1339.

Tibayrenc M, Ward P, Moya A, Ayala F J 1986. Natural populations of Trypanosoma cruzi, the agent of Chagas' disease, have a complex multiclonal structure. Proc Natl Acad Sci USA 83: 115-119.

Toledo MJO, Bahia MT, Carneiro CM, Martins-Filho OA, Tibayrenc M, Barnabé C, Tafuri WL, Lana M 2003. Chemotherapy with benznidazole and itraconazole for mice infected with different Trypanosoma cruzi clonal genotypes. Antimicrob Agents Chemother 47: 223-230.

Toledo MJO, Lana M, Carneiro CM, Bahia MT, MachadoCoelho GLL, Veloso VM, Barnabé C, Tibayrenc M, Tafuri WL 2002. Impact of Trypanosoma cruzi clonal evolution on its biological properties in mice. Exp Parasitol 100: 161172. 